\title{
في نقد مقولة "أهل الرأي وأهل الحديث"
}

\section{* عبد الحميد الإدريسي}

يكاد يكصل اليوم إجماع -أو شيء كالإجماع- بين الذين كتبوا في تاريخ التشريع الإسلامي على أن الفقه الإسلامي منذ نشأته تقاسمته مدرستان: مدرسة أهل الرأي، ومدرسة أهل الحميث. يمكن الرجوع في تبين هذه المقولة واستجالاء بجموع كل المفردات الفكرية المشكِكلة لمضموها مما سنناقشه في هذه المقالة إلى مؤلفات تاريخ التشريع الإسلامي على اختلافها، إذ كلها تكاد تكرر نفس الفكرة بتفاصيلها وجزئياتا، وتبدى فيها وتعيد.

وعندي، أن هذه المقولة تحتاج إلى كثير تدقيق ومراجعة، إذ يسبق إلى الذهن منها - ضرورة- أنه يمكن فهم الدين واستنباط الأحكام الشرعية منه اعتماداً على الحديث وحده، أو على الرأي وحده.

$$
\text { والذي هل همني في هذه العجالة من أمري أن أجيب هنا عن سؤالين اثنين: }
$$

مجاز في الدراسات الإسلامية من كلية الآداب جامعة المولى إسماعيل بمكناس، ويعمل باحثاً في الفقه المالكي وأصوله بدار الحديث الحسنية بالمغرب.

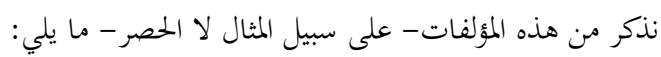

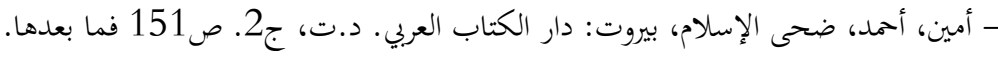

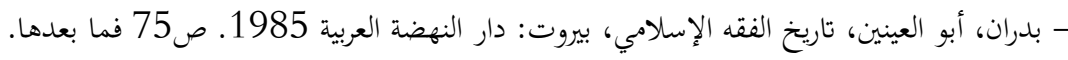

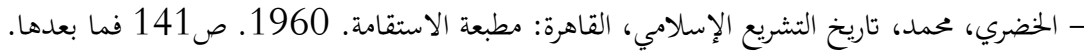

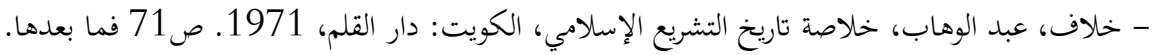

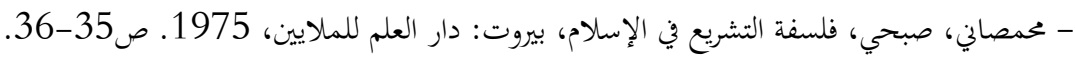

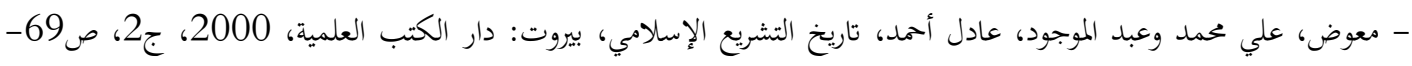

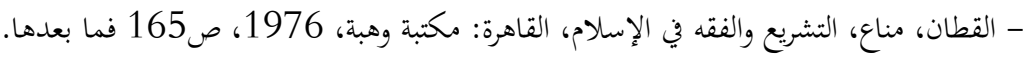

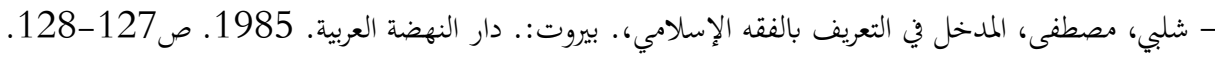

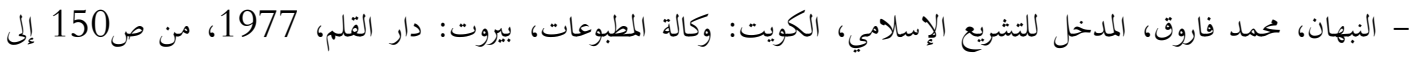

$$
\text { ص157، ومن ص223 إلى ص294. }
$$

- الزرقا، مصطفى، المدخل الفقهي العام، بيروت: دار الفكر صن صناء 1968 /ج 1، ص 167 إلى 170. 
ب. ما السبب الحقيقي في الخلاف الواقع بين مختلف الاتحاهات والمذاهب الفقهية؟

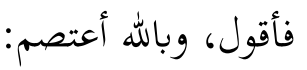

إن ما ينبغي الوقوف عنده -ابتداءً- هو أن الذين يذهبون إلى تقسيم الفقه الإسلامي إلى هاتين المدرستين، لا يتفقون على تحديد موحد لرجال كل واحدة منهما: فلئن كانوا يعتبرون أبا حنيفة زعيم أهل الرأي، فإِهم يختلفون في أهل الحديث من هم؟ فبعضهم يذهب إلى أن مالكاً بالمدينة هو زعيم أهل الحديث، وبعضهم يرى أنه أحمد بالعراق، ويختلفون في الشافعي، فمنهم من يعده من هؤلاء، ومنهم من بعده من أولئك، وكثير منهم يرى أنه جمع بين منهج المدرستين، كما هو مالك عند آخرين، يجمع بين الرأي والحديث، أو محمد بن الحسن تلميذ أبي حنيفة الذي ينظر إليه الكثير على أنه من أصحاب الحديث داخل أهل الرأي، أو سحنون زعيم أهل الرأي داخل مدرسة الحديث، فهذا إشكال أول..

وإشكال ثان، يكمن فيما يزعمه أصحاب هذه المقولة من أن للبيئة والواقع تأثيراً بالغاً في نشوء هاتين المدرستين، إن لم يكن هو السبب الحقيقي في ذلك، وعندها يستروح هؤلاء إلى الحديث عن ثنائية جغرافية متأرجحة بين كل من رقعتي: الحجاز والعراق، فالحجاز -في نظرهم- بيئة حديث وأثر لأنها منبع الرسالة، فكان طبيعياً أن تنشأ بها مدرسة الأثر وتزدهر، والعراق على العكس من ذلك، بيئة تكثر فيها الحوادث والفتن، ويقل فيها الحديث والأثر، ويتجرأ الناس لأجل ذلك على الوضع والكذب على رسول الله صلى الله عليه وسلم، وهذا أعظم ما يتكئ عليه هؤلاء في قولم، وهو في الحقيقة أوهن من بيت العنكبوت لو كانوا يعلمون! لسبب بسيط، هو ما ذكرناه في الإشكال الأول، وبالتحديد نتساءل: ما قولكم في وجود أهل الأثر بالعراق كأمد والأوزعي وغيرهم أو وجود أهل الرأي - - بائماً في اعتقاد هؤلاء- بالمدينة كربيعة وغيره... ولا يقولن أحد إن أحمد إنما جاء بعد أن ازدهر الحديث بالعراق، لأنا نقول: لو كان الأمر كذلك فلم لم يتحول أصحاب أبي حنيفة إلى الحديث عند ازدهاره في هذه البيئة، بل لا نسلم أصلاً أن يكون الحديث قليلاً بالعراق، كثيراً بالحجاز، أو على الأصح أن ذلك أمر نسبي ليس إلا، إذ نجد أن ثمة أحاديث ثبتت صحيحة عند العراقيين لم تصل أهل الحجاز أصلاً... ثم نتساءل: هل كانت البيئة بحجر أبا حنيفة على الأخذ -مثلاًبالفقه الافتراضي التوقعي والتوسع في ذلك؟ كلا! فبالعكس كثرة الحوادث والمستجدات -حسب ما يرون - 
كان مما ينبغي أن يغني عن شيء اسمه الافتراضي والتوقع، فالافتراضي ليس من باب استعمال الرأي أو عدمه، إذ ذاك زيادة عن المطلوب.. ونحن لا يمكننا أن نناقش إلا داخل المطلوب، أي في إطار ما يتطلب منا حلولاً وأحكاماً شرعية، والاحتياط والورع الذي كان يمارسه الإمام مالك كخلق معرفي هنا، ألم يكن من الممكن أن يتجاوزه حين يُسأل، فيَسأل، هل حدث هذا أم لم يحدث، أو حين يدس إليه في حلقته من يسأله من أصحاب الافتراضي الأرايتيين.. ومن هنا نعلم غلط هؤلاء حين يقولون -مسايرة لرأيهم هذا- إن مالكاً

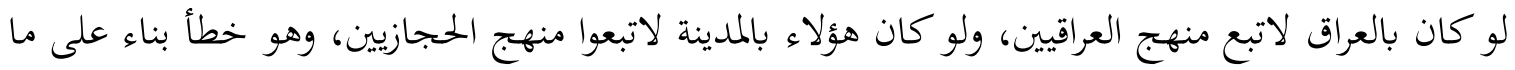
ذكرنا من أن التوسع مثلاً في الأخذ بفقه الحيل والافتراض لا علاقة له ببيئة العراق، وكذا الإكثار من سد الذرائع والاحتياط لا علاقة له ببيئة المدينة، فمالك أيضاً كان يأتيه الناس من كل البلاد -من العراق وغير العراق- بحوادث ومستجدات مختلفة، فلماذا استقر على منهجه ولم يأخذهم بمنهج أهل العراق؟ ثم إن هؤلاء لما كان يخيل إليهم أن كلمة (الرأي) هكذا، شيء مذموم، أو أنه بدعة في الدين وقول من غير دليل، فإهم يحاولون -دفاعاً- أن يلتمسوا مستنداً لمم في ذلك، فيقولون إن زعيم هذا الاتحاه هو عمر بن الخطاب (رضي الله عنه) ومثله علي وابن مسعود.. فهل كان عمر من أهل العراق؟ أم أن علياً وابن مسعود لم ينهجا فهرهما إلا بعد خروجهما من المدينة؟

فإذاً، عامل البيئة والمناخ الاجتماعي لا يمكن أن ندعي أن له كبير أثر في نشوء الاتحاهات الفقهية واختلافها، بل إني لا أرى القضية قضية أثر ورأي، هكذا، بل هي -ابتداءً- قضية اجتهاد، ترتبط بالمجتهد، وقناعاته، وما أداه إليه اجتهاده، فليس صحيحاً أن منهج المدرسة المالكية منهج يغلب فيه الحديث على الرأي، أو منهج المدرسة الحنفية منهج يغلب فيه الرأي على الحديث، بل كل منهما كان يجمع بين الأثر والرأي، ويمزج النقل بالعقل، ويجتهد ما استطاع في إصابة الحكم الشرعي الذي يراه ويعتقد أنه مناط قصد الشارع وحكمته، ومن ثم يوظف ما عنده من أدوات منهجية -عقلاً ونقلاً- بما يفيده في ذلك.

وهنا أجد -في تقديري- ضرورة الإشارة إلى أمر من الأهمية بمكان في هذا الذي أقول: وذلك أن الاختلاف الواقع بين المذاهب الفقهية في أساسه لا يرجع إلى الاختلاف في أصول الاستباط، وأدلة استقاء الأحكام، إذ هذه - في حقيقة الأمر - لا يختلف آحادها من مذهب لآخر، وإنما الاختلاف بالنظر إلى 
مجموعها، أعني أن جوهر الإشكال إنما يكمن في منهج الترتيب من حيث التقديم والتأخير، ومنهج الترجيح من حيث الاعتبار والإهدار، في حالة الاقتران بالنسبة لتلك الأصول، وشاهد ذلك عندي، بالنسبة لتلك المناهج على اختلافها، أنك إذا رأيت ثم رأيت - في حقيقة الأمر - أنه لا انفراد لواحد منها بأصل أو دليل لا يوجد في غيره، فمعظم القضايا الإشكالية في مجال أدلة الفقه الإجمالية نجد التسليم بأصولها وأسسها عند كل إمام من الأئمة المجتهدين، فعلى سبيل المثال: الكل يأخذ بأخبار الآحاد، ولا أحد ينكرها، وكذا الشأن بالنسبة لأقوال الصحابة، والقياس، والمصالح، والاستحسان، والذرائع، والأعراف، وغير ذلك.. وهذا حتى عند من بتنا نردد أنه لا يأخذ بالاستحسان أو المصالح أو الذرائع كالشافعي مثلاً.. لكن، صحيح أن ثثمة اختلافاً في منهج هذا الأخذ، وضوابطه، وأدوات توظيفه، وذلك مما يعود إلى قناعات هؤلاء الأئمة واجتهاداقم التي تنقدح في أذهافم، وتغلب على ظنوغم، وهم بها متعبدون.. والحق أن هذا الذي أشرت إليه ليس بدعاً من القول، بل له من الأدلة والبراهين ما لا يتسع المقام للخوض فيه.

غير أنه لا بد هنا من بعض الاستفزاز العقلي -منهجاً هذه المرة- بتحه هذا الذي نناقشه مما يمكن أن نحسبه فعلاً: عقيدة معرفية راسخة عند من يؤرخون للتشريع فمن يرى أن مالكاً كان من أهل الحديث لا من أهل الرأي، فبماذا يجيب إذا علمنا أنه كان يأخذ بالمصلحة المرسلة ويتوسع فيها أكثر من أبي حنيفة.. ومن غلط بعض الناس هنا أفم فهموا أن مالكاً كان يأخذ بالمصلحة عند عدم وجود النص فقط.. وذهب

$$
2
$$

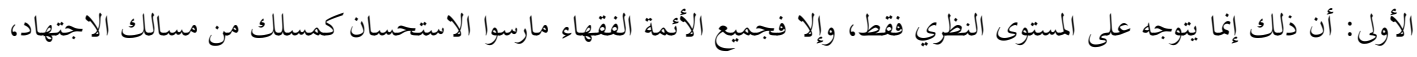

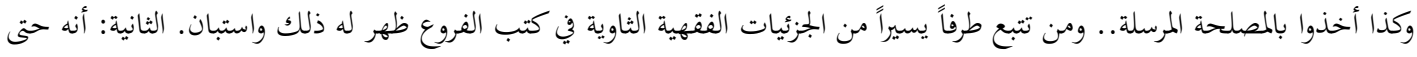

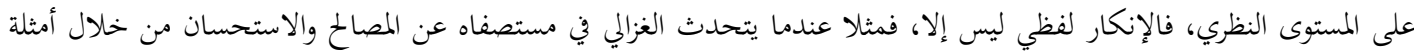

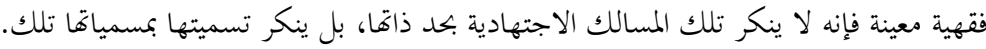

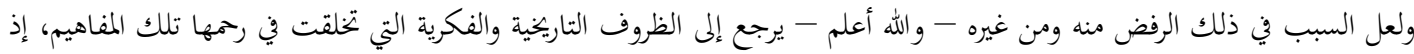

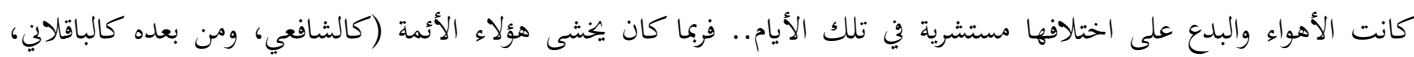

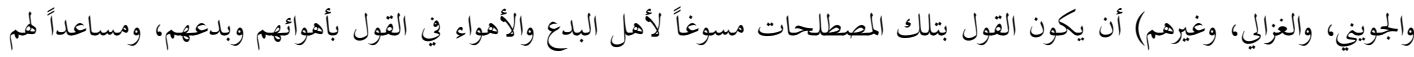

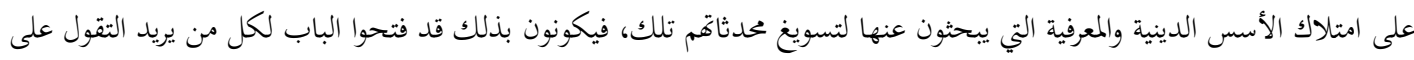

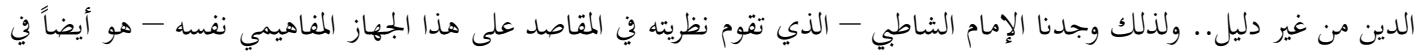

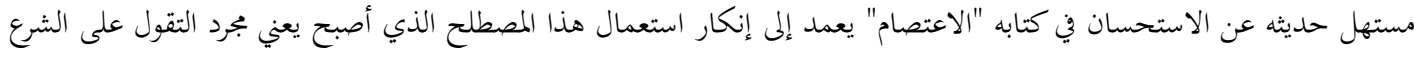

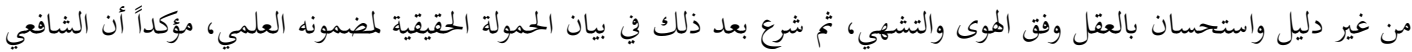
لا لايمكن أن يورد مثل ذلك أصلا. 
بعضهم إلى أن ذلك هو مفهوم الاستحسان عنده! وهو مخطئ كل الخطأ، بل مالك رمه الله كان يخصص النص بالمصلحة، والقياس، والعرف، والضرورة، ورفع الحرج، وغير ذلك. وما جوابنا حين نجد أن مالكاً كان يرى القياس في الحدود والكفارات، وأبو حنيفة لا يراه -نظرياً على الأقل كما يذكر أصحابه- وهو بزعمهم زعيم الرأي وأهله، لا أحد غيره! بل بالغ مالك في القياس وأكثر منه إلى حد أنه كان يقيس على الفروع الثابتة هي نفسها بطريق القياس والاستباط، وماذا نقول عن الإكثار من اعتبار الذرائع والأعراف إلى درجة المبالغة في ذلك، أليس هذا كله من مسالك الرأي، ومنازع العقل، ولعل هذا ما جعل ابن رشد بالمقابل يعتبر مالكاً زعيم أهل الرأي والقياس بل أمير المؤمنين في ذلك! وأبو حنيفة ألم يكن يرى تخصيص القياس بخير الواحد، والتخصيص نوع من الترجيح إن لم يكن ترجيحاً بالكلية، وحكي عنه رمه الله أنه كان لا يقول بدليل الخطاب ولا يعتبره، وتخصيصه لكثير من الآثار بأصول الشرع وقواعده العامة منهج كان مالك يعتمده، بل عندي كما كنت قد أشرت، أن كثيراً من الأحكام عند العراقيين بنيت على أحاديث لم تكن عند أهل الحجاز، بل كانوا يعتمدون على أحاديث ضعيفة أو منكرة، وهذا رداً على من يقول إفم كانوا يتشددون في شروط قبول الأخبار لكثرة الوضع واحتمال الكذب، فلذلك فروا إلى الرأي، ثم كيف نجيب أيضاً عما نجده من مخالفة أتباع أبي حنيفة له في كثير من الأحكام، وكذلك الشأن بالنسبة لمالك، أفلم يكن حرياً بكل مدرسة أن تلتزم بصراطها المنهجي الذي ارتضته لنفسها، بل أحياناً يجتمع مالك وأبو حنيفة على رأي واحد، ويكون مما يجوز -أو نقول- مما يجب فيه الاختلاف بناء على ثنائية (أدلة العقل وأدلة النقل)، ثم لا يختلفان، بل أحياناً يقرر أحدهما أو غيرهما قاعدة من قواعد أصول الفقه عنده، ثم لا يلتزم بها في كثير من الفروع والجزئيات، إلى كثير من الأسئلة الحقيقية في المنهج، مما لا يمكن تتبعه واستقصاؤه في مثل هذه العجالة.. وبالجملة، فإن هذا كله مما يدل على أن القضية قضية اجتهاد محض، ليس إلا، اجتهاد في ترتيب الأدلة وترجيح بعضها على بعض؛ إذ في كثير من الأحيان لا يكون الاختلاف راجع إلى ثنائية الحديث والرأي، بل يكون اختلاف فقط على مستوى واحد: فأحياناً في فهم الحديث واستنباط الحكم منه، أو ترجيح بعضه على بعض، وأحياناً أخرى في تقدير أدلة العقل وحدها واعتبارها، أو ترجيح رأي على رأي فيها، عند تعارض الاحتمالات وتقارها، لأن مثل هذه الأدلة "يقيد بعضها بعضاً، ويخصص بعضها بعضا كما في

$$
3
$$


الأدلة السنية مع القرآنة"، 4 وهذا مما لا خلاف فيه بين أحد.. وأحياناً لا يكون الاختلاف في مدى تحقق مناط الحكم، حسب نظر المجتهد في النازلة التي يجتهد في استنباط حكم شرعي لها، فتكون القاعدة مسلمة عند الجميع، لكن اختلاف المدارك الاجتهادية يجعل البعض يجري القاعدة على أصلها، لأنه يرى ذلك كذلك، والبعض الآخر يعطلها لأنه لم ينقدح في ذهنه صوابية إجرائها، وأرجحية استعمالها.. فإذاً الأمر أمر بحث واجتهاد وسعي من أجل إصابة قصد الشارع - كما يراه المجتهد- بناء على النظر في مآلات الأمور، واعتبار عواقبها.

ومن ثم يمكن أن نخلص إلى أنه رغم ما يظهر من اختلاف بين الأئمة أصحاب المدارس الفقهية "فإنما الجميع محومون على قول واحد هو قصد الشارع عند المجتهد"5 -حسب تعبير الإمام الشاطبي- كما أنه لا يمكن أن نتحدث عن مدرستين: مدرسة الرأي، ومدرسة الأثر، بل يتعين أن نتحدث عن مدارس فقهية مختلفة، ومتعددة بتعدد أصحاهما، وتفاوت قدراقم، واختلاف ابتحهاتم في الاجتهاد والفهم، وترتيب الأدلة وترجيح بعضها على بعض، وإلا فإنه كما قلنا لا يمكن لأحد أن يفهم الوحي بلا عقل، أو يتبع الأثر دون رأي، وذلك حال المدارس الفقهية على اختلافها، ولعل هذا المعنى مما حدا بعدد من العلماء إلى إشارات وإسهامات منهجية سليمة في هذا الاتحاه.. فهذا الإمام ابن تيمية يؤلف كتاباً في "درء تعارض العقل والنقل" مبيناً فيه حاجة كل منهما للآخر، وكذا الإمام الشاطبي ألف كتابه "الموافقات" محاولاً -لا أقول أن يوفق بل أن يكشف التوافق الحاصل حقيقة وسلفاً بين كل من مذهب مالك وأبي حنيفة، ولقد وفق في ذلك أيما توفيق رمة الله عليه.. - مالم

وإذا كان الأمر كذلك فإنه لا يبعد أن يكون الأصح أن نقسم ابحاهات الفقه الإسلامي عامة، وفق رؤية أخرى إلى ابتحهين اثنين: ابتحاه مقاصدي ينفذ إلى روح النصوص ومعانيها، وفي ساحة هذا الاتحاه بالذات وعلى أرضه كان يجري التقسيم القديم الذي حاولنا مناقشته في هذه المقالة.. وابتحه آخر على سلى العكس تماماً إنما ينظر إلى ظواهر النصوص وألفاظها، ويقف عند ذلك لا يتعداه، وهذا الاتحاه لا يقتصر على أهل الظاهر ممن يزعمون إنكار القياس، بل يشمل غيرهم ممن شأفم على خلاف منهج المدرسة

$$
\begin{aligned}
& 4 \\
& 5
\end{aligned}
$$


الأولى... وعلى هذا الأساس يمكن إعادة قراءة تاريخ الفكر الفقهي في الإسلام، وتناول إشكالاته وقضاياه العلمية من هذه الزاوية.

وبعد، فإن غرضي في هذه المقالة أن أثير عدداً من التساؤلات، وأقدّم رأياً آخر في قضية تُعدّ من أهم قضايا فكرنا التشريعي مما يحتاج إلى مزيد بحث ودراسة.. ولما كان هدف ذلك الآن مجرد الاستفزاز المعريف، وإثارة السؤال، فضلت لذلك أن لا أتوسع في الكلام، اكتفاء بما عرف من الأدلة واستبان، مما لا يحتاج إلى كي كثرة توثيق أو برهان، و الله سبحانه وتعالى المستعان. 